\title{
Guided growth for valgus deformity correction of knees in a girl with osteopetrosis: a case report
}

\author{
Dmitry Popkov ${ }^{1}$
}

Received: 21 June 2016/ Accepted: 1 June 2017 / Published online: 7 June 2017

(C) The Author(s) 2017. This article is an open access publication

\begin{abstract}
Autosomal dominant osteopetrosis (AlbersSchönberg disease) classically displays the radiographic signs of osteosclerosis. The main ADO complications involve the skeleton: low-impact bone fractures, scoliosis and hip osteoarthritis. Management of osteopetrosis-related orthopedic problems is a surgical challenge due to increased bone density. The healing process is very slow in these patients because of bone remodeling defects related to osteoblast function failure. In case of bone deformities, a realignment method should be appropriated to osteopetrosis conditions. This article presents a case report of operative treatment of an 11-year-old girl affected with ADO, who underwent a simultaneous valgus knee deformity correction of both limbs with medial eight-plate epiphysiodesis. Simultaneous correction of valgus deformity on both limbs using an extraperiosteal tension plate technique for medial tibial hemiepiphysiodesis was performed in a girl of 11.5 years old with autosomal dominant osteopetrosis. The treatment duration from surgery to complete deformity correction and removal of plates was 18 months. The final aMPTA was $86^{\circ}$ on the right side and $85^{\circ}$ on the left side. The correction rate was $0.61 \%$ month (right tibia) and $0.67 \%$ month (left tibia). The MAD correction rate was evaluated as $1.5 \mathrm{~mm} / \mathrm{month}$ for the right limb and $1.6 \mathrm{~mm} / \mathrm{month}$ for the left limb. At the moment of plate removal, one screw was broken because of tight fixation in osteopetrotic bone. But it did not compromise the final result. The latest follow-up visit at the age of 14 years
\end{abstract}

Dmitry Popkov

dpopkov@mail.ru

1 Russian Ilizarov Scientific Center for Restorative Traumatology and Orthopaedics, 6, M.Ulyanova Street, Kurgan, Russian Federation 640014
6 months revealed excellent realignment without any deformity relapse. There was no any functional impairment. We consider the guided growth by tension band technique as very interesting and promising solution for treatment of pediatric angular deformity in patients with OP. This method allows to avoid osteotomy and related important risk of delayed union or nonunion frequently observed in osteopetrosis.

Level of evidence: Level IV.

Keywords Osteopetrosis - Genu valgum - Tension band technique hemiepiphysiodesis · Guided growth

\section{Introduction}

Osteopetrosis (OP) comprises a set of rare clinically heterogeneous diseases characterized by increased bone mass [1-3]. The increase in bone density results from defective osteoclast differentiation or function $[1,3]$. The incidence of OP is difficult to estimate. Autosomal recessive osteopetrosis (ARO) has an incidence of 1-3.4 in 250,000 live births [4-6]. Overall incidence is 1 in 20,000 births for autosomal dominant osteopetrosis (ADO) [5, 6].

ARO presents the most severe forms diagnosed in the first months of life $[1,7,8]$. The increase in bone density weakens the bone, resulting in predisposition to fractures and osteomyelitis. The impaired longitudinal growth and short stature are classical for the ARO. Children have typical facial appearance (macrocephaly and frontal bossing). The skull changes can lead to hydrocephalus and hindbrain posterior fossa crowding [7]. Pancytopenia because of bone marrow suppression is the most severe complication of ARO [1]. Cranial nerve compressions can result in blindness, deafness and palsy. In severe forms, the 
life expectancy without hematopoietic stem cell transplantation is reduced: Untreated children die in the first decade as a complication of bone marrow suppression [9-11].

ADO has late onset in childhood or adolescence. In contrast to ARO, the life expectancy in these forms is regular [1, 12-14]. In ADO, the genetic mutation in the chloride channel 7 gene (CLCN7) is detected in about 70\% of patients [15]. Albers-Schönberg disease classically displays the radiographic signs of osteosclerosis at the vertebral level, a bone in bone aspect, alternating dense and light bands [1, 2, 12]. The main ADO complications involve the skeleton: bone fractures (with mean of 3 fractures per patient), scoliosis, hip arthritis, mandibular osteomyelitis and dental abscess [1, 13, 14, 16]. On the other hand, cranial nerve compressions and short stature are rare [1, 14]. Management of osteopetrosis-related fractures presents a surgical challenge due to increased bone density $[14,17]$. Furthermore, the healing process is very slow in these patients because of bone remodeling defects related to osteoblast function failure (low rate of bone turnover) $[2,18,19]$. Nonunion or delayed bone union might occur $[14,17,19,20]$. There are a lot of case reports regarding the treatment of osteopetrosis-related fractures in references [13, 14, 16, 20-23]. But in bone deformities due to impaired growth or malunion of a fracture, realignment methods should be appropriated to osteopetrosis conditions as well. We did not find any study or case report published about deformity correction of lower limbs in children with osteopetrosis. Only one paper concerning the result of a case of lower limb length discrepancy correction was found [24].

This article presents a case report of operative treatment of an 11-year-old girl affected with ADO, who underwent a simultaneous valgus knee deformity correction of both limbs with medial eight-plate epiphysiodesis.

\section{Materials and methods}

In our institution, a girl of 11 years 1 month old (height $144 \mathrm{~cm}$, weight $37 \mathrm{~kg}$ ) was examined because of valgus deformity of the knee and a year history of moderate anterior knee pain related to physical activity. Symmetric valgus knee deformity had gradually been progressing for recent 18 months according to the parent's opinion. Bilateral genu valgum caused circumduction gait.

During a physical examination, the patient had evident valgus deformity of both knees (Fig. 1). Range of motion in knees, hips and ankles was not limited. But within the latest year, a walking distance did not exceed $2 \mathrm{~km}$. Ocular examination revealed slight bilateral vision loss. Other systemic examinations showed normal vital findings. Laboratory tests were within normal limits, except mild anemia (erythrocytes $3.9 \times 10^{6} \mathrm{ml}$; hemoglobin $108 \mathrm{~g} / \mathrm{l}$ ). Patient's history revealed two asynchronous femoral neck fractures at the age of 7 years. Conservative management was satisfactory without development of coxa vara (Fig. 1). The family history of the patient did not indicate osteopetrosis. The parents available for examination revealed no manifestation of osteopetrosis.

$\mathrm{X}$-ray examinations revealed diffuse osteosclerosis, affecting spine, pelvis and long bones with bone modeling defects at the metaphyses (Fig. 1). We used several standard criteria to evaluate radiological parameters [25]. The anatomical lateral distal femoral angle (aLDFA) was $84^{\circ}$ (right side) and $82^{\circ}$ (left side). Values of anatomical medial proximal tibial angle (aMPTA) were pathological and corresponded to valgus deformity: $97^{\circ}$ for both tibias. That deformity determined lateral mechanical axis deviation (MAD) of $24 \mathrm{~mm}$ on the right limb and $25 \mathrm{~mm}$ on the left limb. No deformities were detected in the lateral plane.

For simultaneous correction of valgus deformity on the both limbs, we performed extraperiosteal tension band technique (eight-plate) medial tibial hemiepiphysiodesis in 6 months after the first visit. The guided growth is the most low-invasive method in pediatric deformity correction. It avoids any kind of complications caused by osteotomy and osteosynthesis (Fig. 2).

Application of eight plates was performed under general anesthesia via standard approaches. We used slow-speed high-torque electric drills and frequent cooling with physiological saline while preparing canals for screws. No immobilization was required after surgery, and early weight bearing was encouraged with a rapid return to normal activities. Follow-up evaluation (AP weight-bearing X-rays and clinical examination) was performed every 3 months approximately because the rate of angular deformity correction in children with $\mathrm{OP}$ is unclear (Fig. 3).

\section{Results}

The treatment duration from surgery to removal of plates (realignment achieved) was 18 months. During treatment, we observed progressive clinical and radiological correction of valgus knee deformity. The final aMPTA was $86^{\circ}$ on the right side and $85^{\circ}$ on the left side so that the degree corrected was $11^{\circ}$ for the right tibia and $12^{\circ}$ for the left tibia. The correction rate was $0.61 \%$ month (right tibia) and $0.67 \%$ month (left tibia). At the moment of plate removal, the medial MAD corresponded to normal realignment in children of that age [26]: medial position of $3 \mathrm{~mm}$ to center 
a

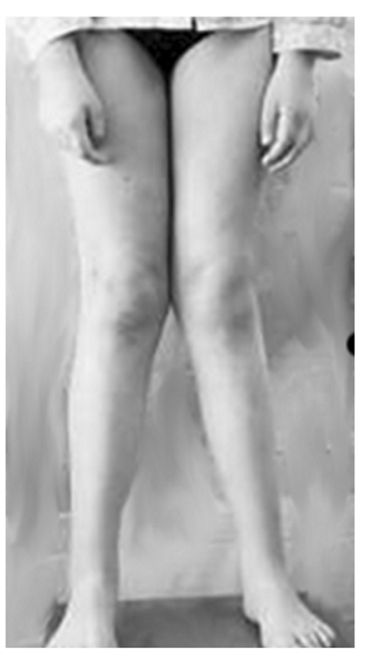

C

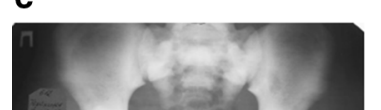

b
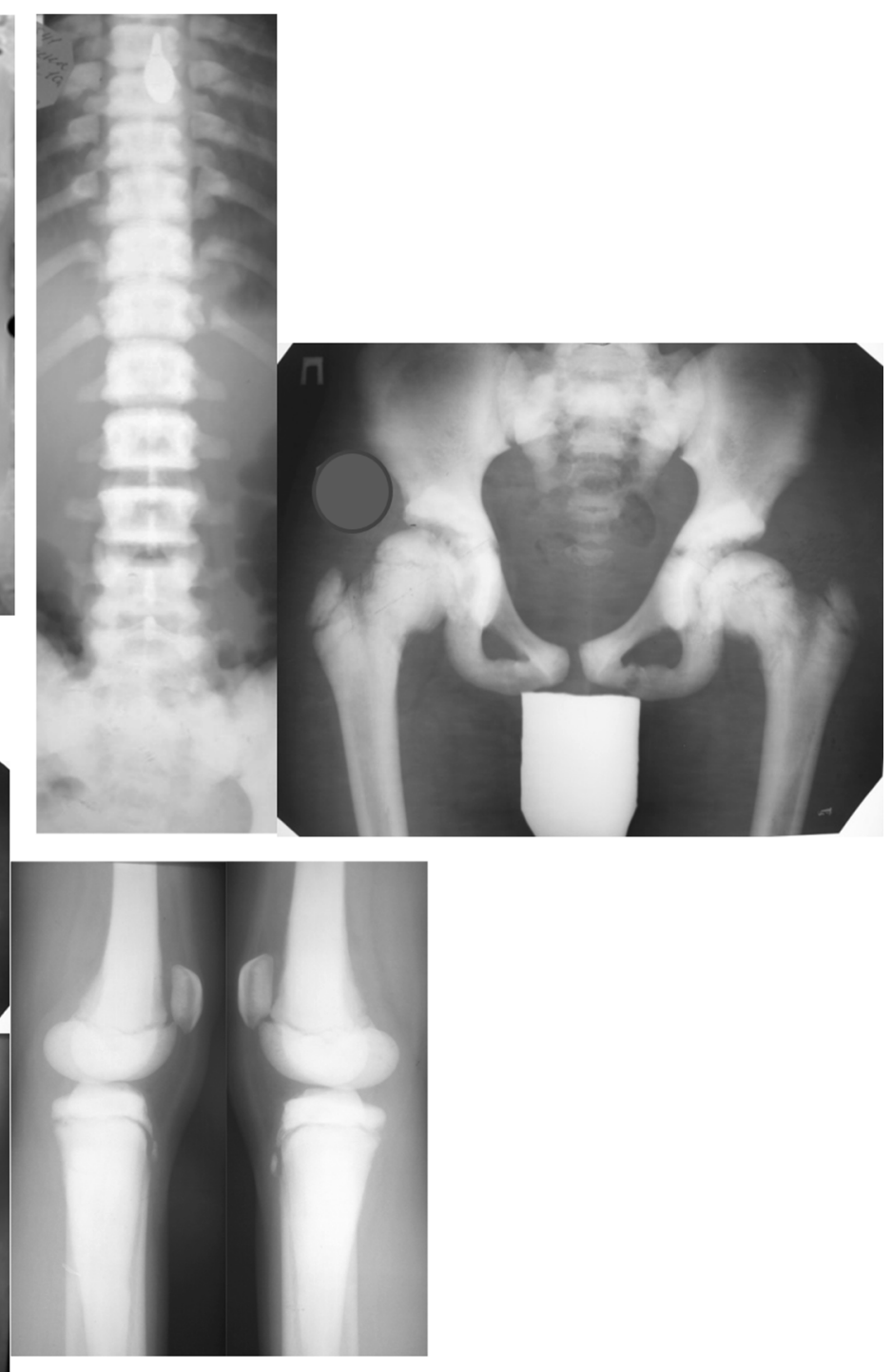

Fig. 1 Before surgery: a aspect of lower limbs; b AP radiographs of the spine and pelvis, note increased bone density; c radiographs of lower limbs: aLDFA $84^{\circ}$ (right side) and $82^{\circ}$ (left side); aMPTA $97^{\circ}$ for both tibias

of right knee joint and $4 \mathrm{~mm}$ medial to center of left knee joint. The MAD correction rate was evaluated as $1.5 \mathrm{~mm} / \mathrm{month}$ on the right and $1.6 \mathrm{~mm} / \mathrm{month}$ on the left (Fig. 4).

At the moment of plate removal, one screw was broken because of tight fixation in osteopetrotic bone. But it did not compromise the final result (Fig. 5).
At the latest follow-up visit at the age of 14 years 6 months old (menstruation occurred), clinical realignment was excellent without any deformity rebound. There was no any functional impairment. We did not observe the decrease in range of motion in the knee. The patient refused an X-ray control in order to reduce irradiation, and we did not insist because the clinical result was absolutely satisfactory (Fig. 6). 


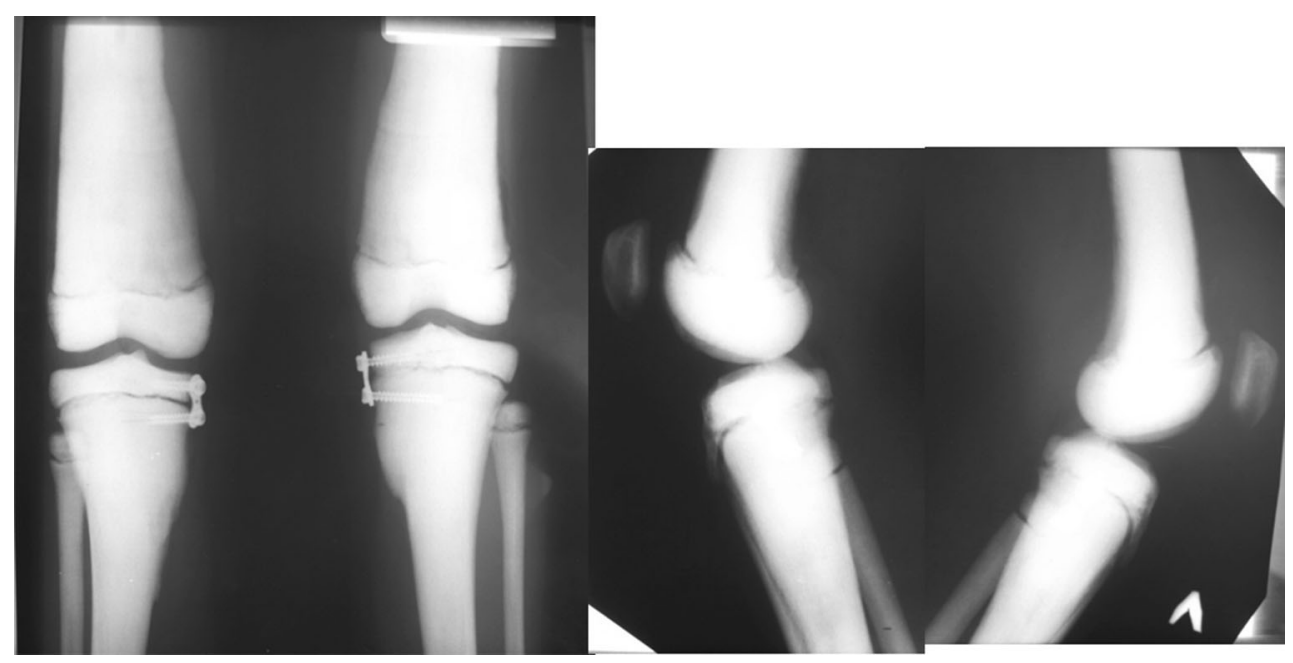

Fig. 2 AP and lateral knee radiographs of lower limbs after surgery

a

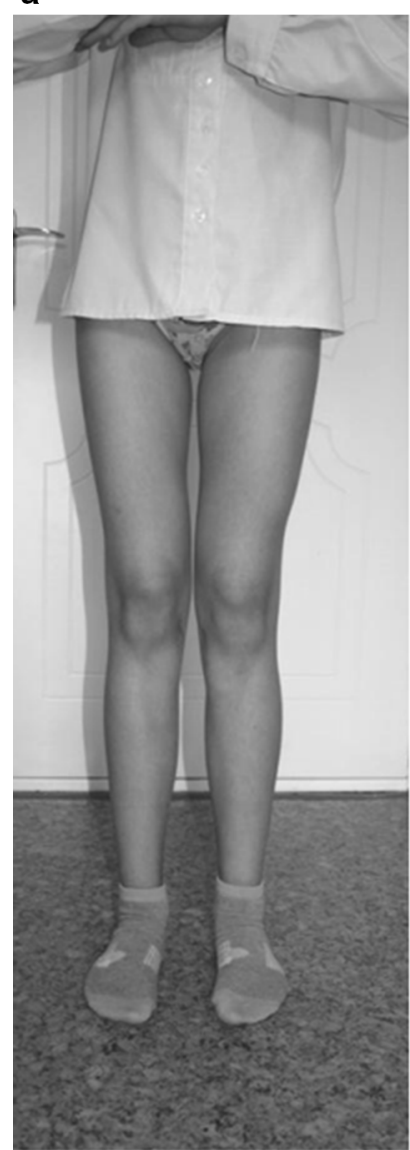

b

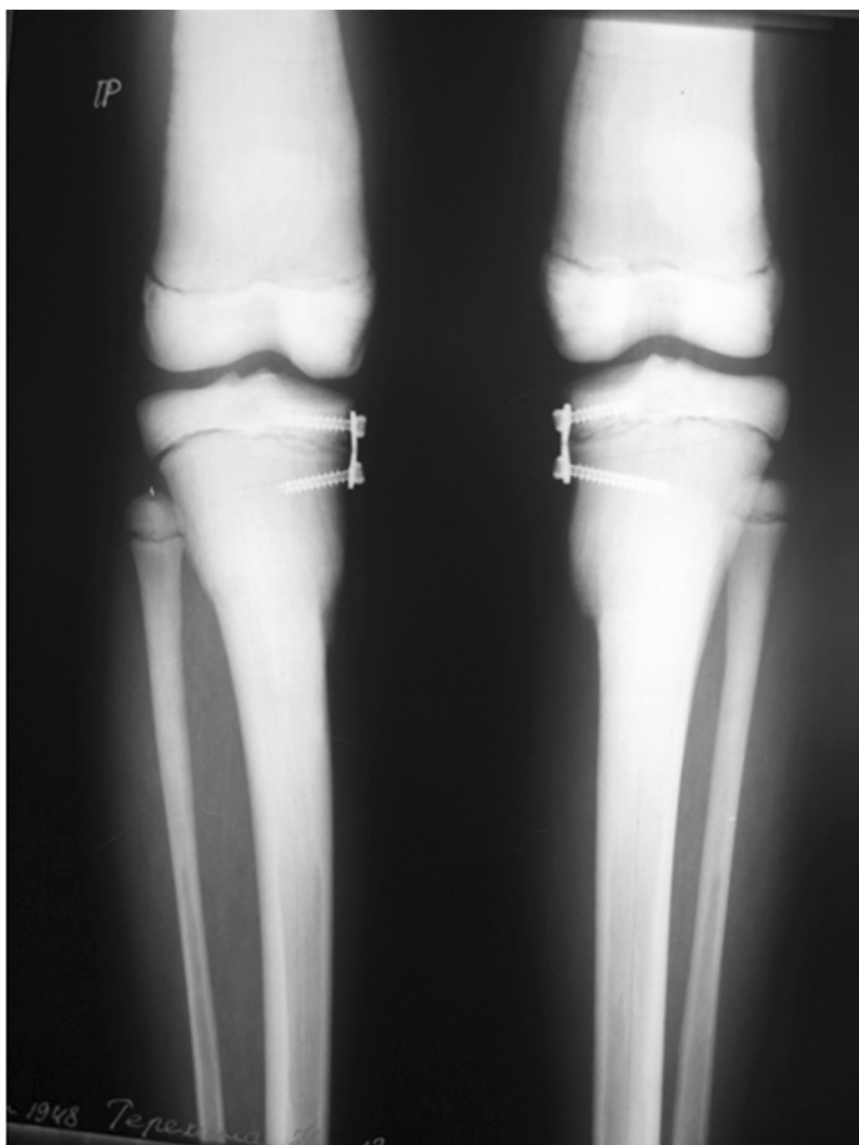

Fig. 3 During treatment: a lower limb aspect in 9 months after surgery; b AP radiographs of lower limbs in 12 months after eight-plate implant

\section{Discussion}

Angular knee deformities alter biomechanics of the limb by causing a distorted stress distribution on the weight-bearing surface of the knee joint [27]. Surgical intervention should be considered for a deformity exceeding $10^{\circ}$ with a predicted remaining time for growth of at least 12 months [28]. The eight-plate hemiepiphysiodesis method is often preferred for pediatric angular deformity correction as a low-invasive method to restore lower limb realignment [28-31]. 


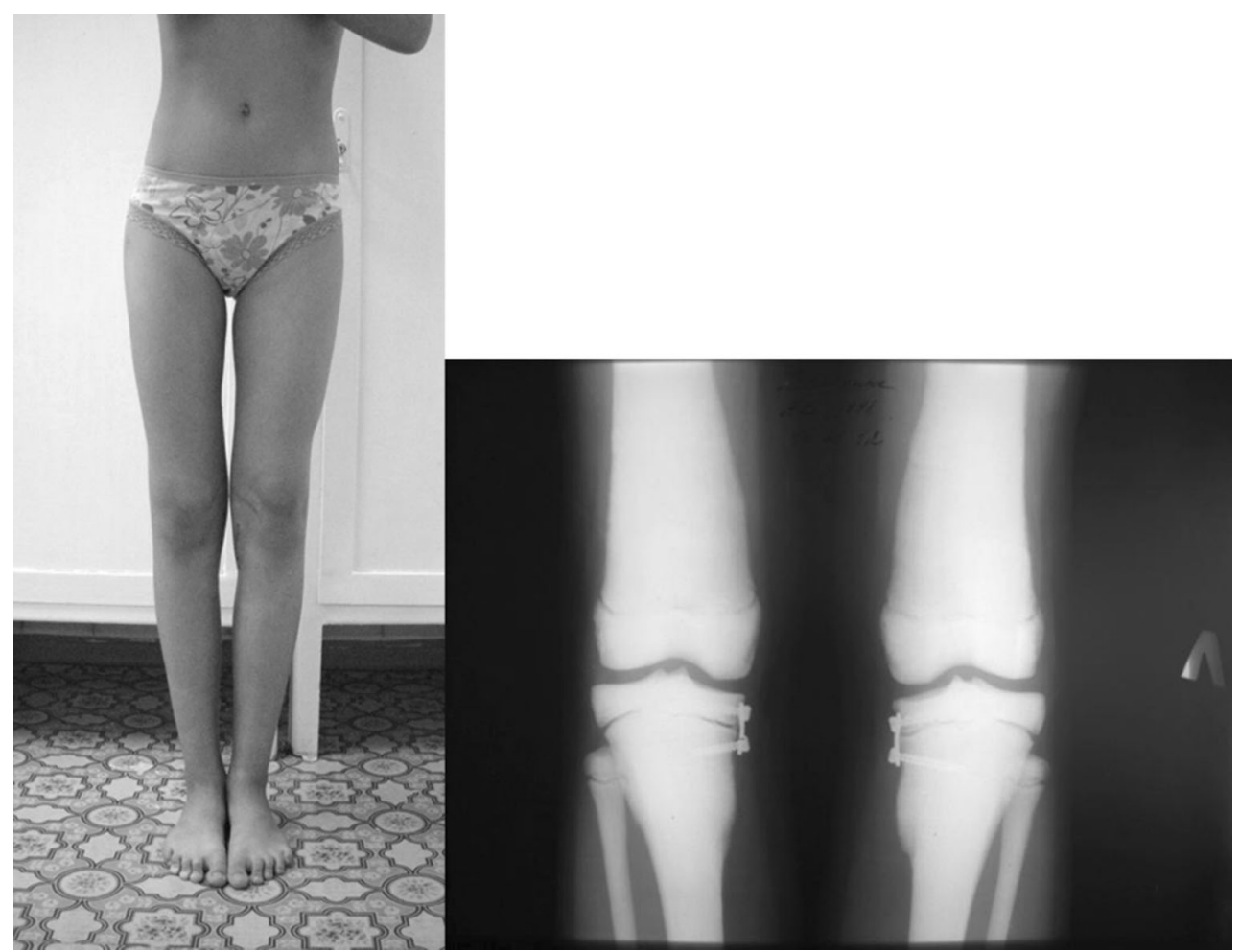

Fig. 4 In 18 months after surgery, surgery plates removal is planned

In patients with $\mathrm{OP}$, the increased bone mass is observed due to osteoblast dysfunction $[1,3,6,15]$ and bone fragility_due to abnormal remodeling rate and balance [18, 32]. Arruda et al. [33] found a great heterogeneity in bone microstructure in adult patients with ADO, using $\mathrm{X}$-ray absorptiometry and high-resolution peripheral quantitative computed tomography. They showed that the accumulation of old and fragile bone randomly distributed along the skeleton. These alterations in bone microstructure may contribute to high prevalence of low-impact fractures in patients with $\mathrm{ADO}[12,13,16,33]$. On the other hand, the osteopetrotic bone consolidates with pathological callus without Haversian organization due to osteoclast function failure [34].

The dominant types of OP are more clinically challenging because of normal life expectancy in comparison with recessive (malignant) forms $[1,3,17,35,36]$. The main orthopedic problems in children and adults with ADO are low-impact fractures, coxa vara, osteoarthritis and osteomyelitis [12, 14, 18, 19].

The publications about osteopetrotic fractures, especially femoral fractures, and their treatment are common. The majority of colleagues suggest that the osteosynthesis is the primary treatment of choice in management of osteopetrotic femoral fractures [13, 16, 17, 21-23]. But they report several types of complication related to the surgery due to hard-fragile sclerotic bones: bending of drill bits or screws, and osteomyelitis [12,14]. Delayed union or nonunion of fracture and related implant failure are also reported in the literature [14, 20, 23]. Troubles of bone consolidation in patients with OP are due to remodeling failure of callus [18, 19, 37]. Malunion of femoral fractures can result in coxa vara and develop osteoarthritis of the hip requiring arthroplasty that provides good outcomes [36]. In case of knee osteoarthritis, the results of total knee arthroplasty are also excellent [19].

Very slow bone consolidation and frequently observed implant failures justify the use of the orthopedic methods without bone solution in children with OP. We found only one case of lower limb length discrepancy correction with epiphysiodesis in a 14-year-old girl in references [24]. Inan et al. showed that a percutaneous epiphysiodesis can treat limb length discrepancies in children with osteopetrosis.

In our case, genu valgum deformity correction was done by performing medial extraperiosteal hemiepiphysiodesis by tension band technique. Excellent simultaneous limb realignment was achieved in both limbs in 18 months. During preoperative planning, it was impossible to consider the exact rate of angular deformity correction as spontaneous growth of tibia was pathological in OP condition. However, we did not face any difficulties in this regard, probably, because the epiphyseal plates had a good growth rate. The observed speed of correction in the described case was similar to a correction rate in the group of idiopathic knee deformity in the study of Boero et al. [28]. 
a

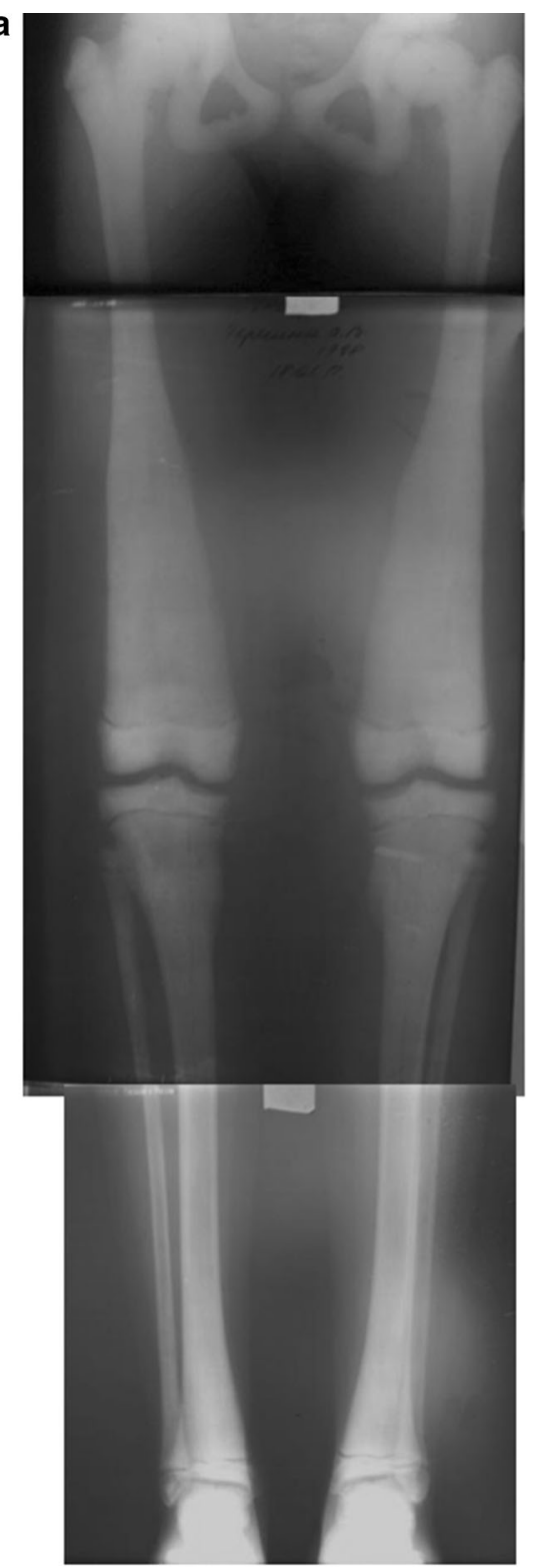

b

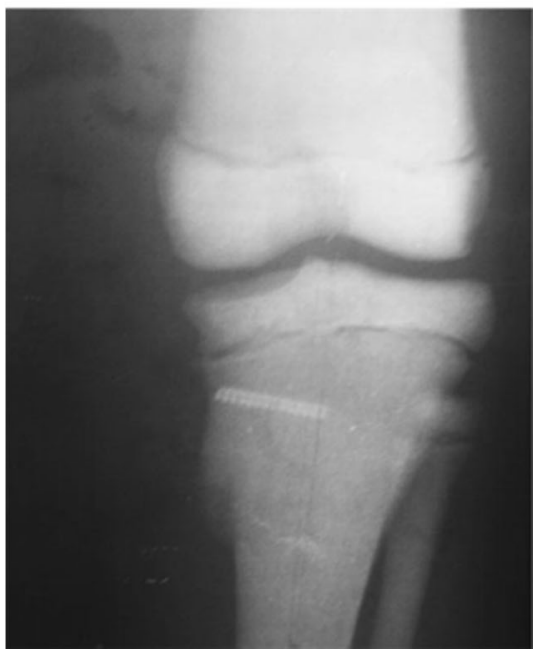

४Fig. 5 Radiographs after frames removal: a aMPTA $86^{\circ}$ (right side) and $85^{\circ}$ (left side); MAD medial position of $3 \mathrm{~mm}$ to center of right knee joint and $4 \mathrm{~mm}$ medial to center of left knee joint; b broken screw in tibial metaphysis

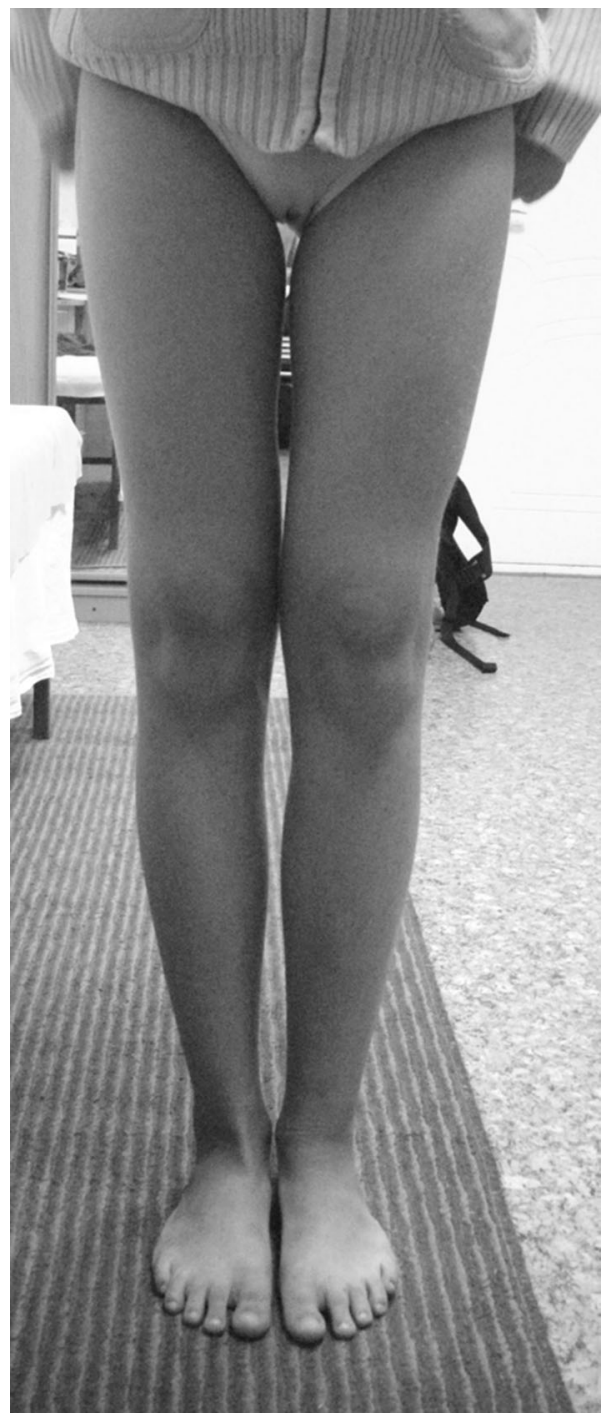

Fig. 6 Patient at the age of 14 years 6 months old

The implant failure was not observed in our patient, but at the moment of material removal one screw was broken because of bone density. It did not compromise the result, but orthopedists should be aware of that eventual complication.

\section{Conclusion}

Thus, we consider the guided growth by tension band technique as a very promising solution for treatment of pediatric angular deformity in patients with OP. This method allows to avoid osteotomy and a related high risk 
of delayed union or nonunion frequently observed in osteopetrosis. Furthermore, limb realignment in these pathological conditions prevents or slows down the development of secondary osteoarthritis.

Acknowledgements The author thanks Natalia Popkova for her assistance in preparing the publication.

\section{Compliance with ethical standards}

Conflicts of interest The author has no competing interest to declare.

Ethical approval All procedures performed in studies involving human participants were in accordance with the ethical standards of the institutional and/or national research committee and with the 1964 Helsinki declaration and its later amendments or comparable ethical standards.

Informed consent Informed consent was obtained from all individual participants included in the study.

Open Access This article is distributed under the terms of the Creative Commons Attribution 4.0 International License (http://crea tivecommons.org/licenses/by/4.0/), which permits unrestricted use, distribution, and reproduction in any medium, provided you give appropriate credit to the original author(s) and the source, provide a link to the Creative Commons license, and indicate if changes were made.

\section{References}

1. Stark Z, Savarirayan R (2009) Osteopetrosis. Orphanet J Rare Dis 20(4):5. doi:10.1186/1750-1172-4-5

2. Skeletal Dysplasia Society (2007) Nosology and classification of genetic skeletal disorders: 2006 revision. Am J Med Genet Part A 143A: $1-18$

3. Coudert AE, de Vernejoul MC, Muraca M, Del Fattore A (2015) Osteopetrosis and its relevance for the discovery of new functions associated with the skeleton. Int J Endocrinol 2015:372156. doi: $10.1155 / 2015 / 372156$

4. Loria-Cortes R, Quesada-Calvo E, Cordero-Chaverri C (1977) Osteopetrosis in children: a report of 26 cases. J Pediatr 91:43-47

5. Bollerslev J, Andersen PE Jr (1988) Radiological, biochemical and hereditary evidence of two types of autosomal dominant osteopetrosis. Bone 9:7-13

6. Rashid BM, Rashid NG, Schulz A, Lahr G, Nore BF (2013) A novel mis-sense mutation in the CLCN7 gene linked to benign autosomal dominant osteopetrosis: a case series. J Med Case Rep 7:7. doi:10.1186/1752-1947-7-7

7. Al-Tamimi YZ, Tyagi AK, Chumas PD, Crimmins DW (2008) Patients with autosomal-recessive osteopetrosis presenting with hydrocephalus and hindbrain posterior fossa crowding. J Neurosurg Pediatr 1:103-106

8. Dozier TS, Duncan IM, Klein AJ, Lambert PR, Key LL Jr (2005) Otologic manifestations of malignant osteopetrosis. Otol Neurotol 26:762-766

9. Driessen GJ, Gerritsen EJ, Fischer A, Fasth A, Hop WC, Veys P, Porta F, Cant A, Steward CG, Vossen JM et al (2003) Long-term outcome of haematopoietic stem cell transplantation in autosomal recessive osteopetrosis: an EBMT report. Bone Marrow Transplant 32:657-663

10. Dini G, Floris R, Garaventa A, Oddone M, De Stefano F, De Marco R, Calcagno E, Faraci M, Claudiani F, Manfredini L, Dallorso S, Lanino E, Morreale G (2000) Long-term follow-up of two children with a variant of mild autosomal recessive osteopetrosis undergoing bone marrow transplantation. Bone Marrow Transplant 26(2):219-224

11. Martinez C, Polgreen LE, DeFor TE, Kivisto T, Petryk A, Tolar J, Orchard PJ (2010) Characterization and management of hypercalcemia following transplantation for osteopetrosis. Bone Marrow Transplant 45(5):939-944. doi:10.1038/bmt.2009.277

12. Shapiro F (1993) Osteopetrosis: current clinical considerations. Clin Orthop 294:34-44

13. Birmingham P, McHale KA (2008) Case reports: treatment of subtrochanteric and ipsilateral femoral neck fractures in an adult with osteopetrosis. Clin Orthop Relat Res 466(8):2002-2008. doi:10.1007/s11999-008-0256-x

14. Aslan A, Baykal YB, Uysal E, Atay T, Kirdemir V, Baydar ML, Aydoğan NH (2014) Surgical treatment of osteopetrosis-related femoral fractures: two case reports and literature review. Case Rep Orthop 2014:891963. doi:10.1155/2014/891963

15. de Vernejoul MC, Schulz A, Kornak U (1993) CLCN7-related osteopetrosis. In: Pagon RA, Adam MP, Ardinger HH, Wallace SE, Amemiya A, Bean LJH, Bird TD, Fong CT, Mefford HC, Smith RJH, Stephens K (eds) GeneReviews ${ }^{\circledR}$ [Internet]. University of Washington, Seattle. 2007 Feb 12 (updated 20 Jun 2013)

16. Chhabra A, Westerlund LE, Kline AJ, McLaughlin R (2005) Management of proximal femoral shaft fractures in osteopetrosis: a case series using internal fixation. Orthopedics 28(6):587-592

17. Cadosch D, Gautschi OP, Brockamp T, Zellweger R (2009) Osteopetrosis - a challenge for the orthopaedic surgeon. S Afr J Surg 47(4):131-133

18. Scaramuzzo L, Messuti L, Manicone PF, Raffaelli L, Rossi B, Gallenzi P, Berardi D, Maccauro G (2009) Clinical and histological modifications in osteopetrotic bone: a review. J Biol Regul Homeost Agents 23(2):59-63

19. Landa J, Margolis N, Di Cesare P (2007) Orthopaedic management of the patient with osteopetrosis. J Am Acad Orthop Surg 15(11):654-662

20. Dong L, He W, Huo S, Guo C, Zhou C, Chen Q, Tang H, Xie X, Wang $H$ (2015) The failure experience of complex total hip arthroplasty in osteopetrosis: case report and literature review. Int J Clin Exp Med 8(9):14727-14731

21. Gupta R, Gupta N (2001) Femoral fractures in osteopetrosis: case reports. J Trauma 51:997-999

22. Nakayama J, Fujioka H, Kurosaka M, Kitazawa H, Maesawa N, Tomioka M (2007) Surgery for clavicular and humeral fractures in an osteopetrotic patient: a case report. J Orthop Surg 15(2):251-254

23. Golden RD, Rodriguez EK (2010) Management of subtrochanteric femur fractures with internal fixation and recombinant human bone morphogenetic protein-7 in a patient with osteopetrosis: a case report. J Med Case Rep 19(4):142. doi:10. 1186/1752-1947-4-142

24. Inan M, Chan G, Bowen JR (2006) Case reports: epiphysiodesis in a patient with osteopetrosis. Clin Orthop Relat Res 450:255-258

25. Chao EY, Neluheni EV, Hsu RW, Paley D (1994) Biomechanics of malalignment. Orthop Clin North Am 25:379-386

26. Popkov D, Lascombes P, Berte N, Hetzel L, Baptista BR, Popkov A, Journeau P (2015) The normal radiological anteroposterior alignment of the lower limb in children. Skeletal Radiol 44(2):197-206. doi:10.1007/s00256-014-1953-z

27. Stevens P (2006) Guided growth: 1933 to the present. Strategies Trauma Limb Reconstr 1(1):29-35

28. Boero S, Michelis MB, Riganti S (2011) Use of the eight-Plate for angular correction of knee deformities due to idiopathic and pathologic physis: initiating treatment according to etiology. J Child Orthop 5(3):209-216. doi:10.1007/s11832-011-0344-4 
29. Stevens PM, Klatt JB (2008) Guided growth for pathological physes: radiographic improvement during realignment. J Pediatr Orthop 28(6):632-639

30. Stevens PM (2007) Guided growth for angular correction: a preliminary series using a tension band plate. J Pediatr Orthop 27(3):253-259

31. Ballal MS, Bruce CE, Nayagam S (2010) Correcting genu varum and genu valgum in children by guided growth: temporary hemiepiphysiodesis using tension band plates. J Bone Joint Surg Br 92(2):273-276

32. Bénichou OD, Laredo JD, de Vernejoul MC (2000) Type II autosomal dominant osteopetrosis (Albers-Schönberg disease): clinical and radiological manifestations in 42 patients. Bone 26:87-93

33. Arruda M, Coelho MC, Moraes AB, de Paula Paranhos-Neto F, Madeira M, Farias ML, Neto LV (2015) Bone mineral density and microarchitecture in patients with autosomal dominant osteopetrosis: a report of two cases. J Bone Miner Res. doi:10. 1002/jbmr.2715

34. De Palma L, Tulli A, Maccauro G, Sabetta SP, Del Torto M (1994) Fracture callus in osteopetrosis. Clin Orthop 308:85-89

35. Armstrong DG, Newfield JT, Gillespie R (1999) Orthopedic management of osteopetrosis: results of a survey and review of the literature. J Pediatr Orthop 19:122-132

36. Girard J, Vendittoli PA, Lavigne M, Roy AG (2006) Resurfacing arthroplasty of the hip in osteopetrosis. J Bone Joint Surg Br 88(6):818-821

37. Krieg AH, Speth BM, Won HY, Brook PD (2007) Conservative management of bilateral femoral neck fractures in a child with autosomal dominant osteopetrosis. Arch Orthop Trauma Surg 127(10):967-970 